\title{
Meditation for stress reduction in Indian Army- An Experimental Study
}

\author{
Col S S Cheema ${ }^{1} \&$ Col D S Grewal ${ }^{2}$ \\ 1. Saint Soldier College of Engineering Jalandher \\ 2. DeshBhagat University MandiGobindgarh
}

\section{Introduction:}

1.1 Stress is defined as "the non-specific response of the body to any demand made upon it." Hans Sely (1956). Lazarous (1966) maintains that stress occurs when demands on the person which tax or exceed his judgment resources. McGrath JE (1990) explains that there is a potential for stress when an environmental situation is perceived as presenting a demand which threatens to exceed the person's capabilities and resources for meeting it under conditions where he has expected a substantial differential in the rewards and cost for meeting the demands verses not meeting it.Stress can be the result of external situations such as an abusive relationship or poor working conditions. Stress can also be the result of internal situations or stressors such as worrying or having pessimistic thoughts about future. Work being the central theme to the life and a social reality provides a status to the individual and his bond to the society by way of quality of work or position he attains. This ultimately leads to raise the standard of living or we can call it desire to grow, so that we can get recognition and social status in the society. In the ambition to grow we begin to work more than our capabilities and thus strain ourselves and thus lead to stress. (Prestonjee DM \&Muncherji (1991)). Duration in stress is another variable which acts as a factor causing stronger stress response. This is in consistence with uncertainty theory of occupational stress by Beer TA and Bhagat RS (1985).Each individual needs a moderate amount of stress to be alert and capable of functioning effectively in an organization. Hence stress is inherent in the concept of creativity. [Pestonjee(1991) Pareek(1993)].

\section{Stress in Defence Forces:}

Stress has been taking heavy toll of Indian Army. Incidents of defence personnel including paramilitary personnel committing suicide and cases of soldiers running amok has become a common phenomenon. On the average over 100 soldiers have been committing suicides annually since 2008.On 19 August 2012, in RajyaSabha, Defense Minister of India Mr. A.K. Antony gave the number of suicides as in Table 1.

Table 1: suicides in Indian Army since 2003

\begin{tabular}{|c|c|c|}
\hline Year & No. of Suicides & Remarks \\
\hline 2012 till July 2012 & 69 & \multirow{10}{*}{$\begin{array}{l}\text { On the average } 110 \\
\text { Army men lose their } \\
\text { life. }\end{array}$} \\
\hline 2011 & 182 & \\
\hline 2010 & 115 & \\
\hline 2009 & 96 & \\
\hline 2008 & 123 & \\
\hline 2007 & 118 & \\
\hline 2006 & 129 & \\
\hline 2005 & 77 & \\
\hline 2004 & 100 & \\
\hline 2003 & 96 & \\
\hline
\end{tabular}

(Reference: The Tribune Chandigarh, 20 Aug. 2012)

2.1 This has been a great cause of concern for the Defence Forces. Not only the human life is lost, it affects the morale of the troops. The suicide rate is increasing inspite of the liberal policy providing various facilities to increase in pay by sixth pay commission, housing projects for army personnel, liberal leave policy etc. The soldiers are still found under tremendous stress culminating into suicides increasingly. Generally known causes of stress in army are frequent changes of places, colleagues and responsibilities, increasing impact of materialism, increasing impact of materialism, operational conditions peculiar to low intensity combat (LIC)

2.2: No organization in the world caters for large scale changes than the armed forces. Change of unit location (often from hot desert to snow bound mountains) change of seniors/ colleagues/ subordinates, change of dwelling places, change of job content, change of schools for children etc., are a few examples of routine changes. 
2.3 Increasing impact of materialism: Defence establishment of India are considered the most dependable, secular and non-political institution of Indian democracy. Majority of the members of Armed Forces still have simple outlook to life and negligible living requirements. Due to the rapid changes in science and technology however, socio-economic environment has made the soldiers, material minded and easy life oriented. This awareness has caused changes in their working environment wherein lies the key of the problem.

2.4 Increasing impact of materialism: The profession of Armed Forces has the 'round the clock on duty' requirement. With the advancement of means of communications, the thin line of domain of office and house has merged. Crumbling of joint family system has eroded family support base to a large extent and created the following problems.

(a) The responsibility of welfare of the family has now become the sole duty of the individual soldier.

(b) Prolonged separation from the family due to organizational commitment puts strain on marital fidelity and causes marital stress.

(c) A sense of inability to look after the family under excessive abuse and humiliation at home creates a guilty feeling in the individual soldier which in turn creates tremendous stress on the individual.

2.5 Operational Conditions Peculiar to Low Intensity Combat (LIC): The fear of the unknown, continuously looming danger and prolonged feelings of loneliness, take a heavy toll of the patience of the soldier, when under low intensity combat (LIC). There is no simple solution to combat LIC. It requires patience, skill and sustained effort to combat LIC. In LIC there is a disproportional requirement of resources in terms of troops, equipment and finances.

2.6 Combat Stress and Fatigue: Incidents of some middle level officers in the army committing suicides and cases of soldiers running amok, shooting at their seniors are because of their being under tremendous stress. This disturbing trend is bound to affect the morale of the troops and officers, the only factor which keeps this force going.

\section{Conceptual Variables And Theoretical Understanding:}

Health as defined by WHO is a state of complete physical, mental and social wellbeing and not merely absence of disease in your mind and spirit. Stress being a serious ailment thus needs special treatment. Everyone has different response to stress. Likewise everyone has a different sign of symptom of stress, depending on their temperament and life situation. Thus the behavioral aspects of stress too are to be kept in mind. This makes the problem complicated hence must be treated as such.

\section{The dynamics of stress:}

4.1 In a challenging situation the brain prepares the body for defensive action i.e., the fight or flight response by releasing stress hormones, normally, cortisone and adrenaline. These hormones raise blood pressure and the body prepares to react to the situation. With a concrete defensive action (fight response) the stress hormones in the blood get used up, entailing reduced stress effects and symptoms of anxiety.

4.2 When we fail to counter a stress situation (flight response) the hormones and the chemicals remain unreleased in the blood stream for a long time period. It results in stress related physical symptoms such as tense muscles, unfocussed anxiety, dizziness and rapid heartbeats. We all encounter various stresses in everyday life; which; can accumulate, if not released. Subsequently, it compels the mind and the body to be in an almost constant alarm state in preparation to fight or flee. This state of accumulated stress can increase the risk of both, acute or chronic psychometric illness and weaken the immune system.

4.3 Methods of coping with stress are plenty. The most significant or sensible way out is a change in life style. Relaxation techniques such as meditation, physical exercises, listening to the soothing music, deep breathing, and various natural and alternative methods, personal growth techniques, visualizing and massage are some of the most effective methods of the known non-invasive stress busters.

\section{Spiritual and Psychological Stress}

5.1 Most causes of psychological stress are perennially related to emotional and psychological disorders. Stressful situations, whether long-term or short-term, can set forth series of emotional symptoms, like feeling of personality disintegration, phobia, anxiety attacks, unfocused attention, exaggerated emotional responses and psychological discomposure such as depression, confusion burnout and never forget the resultant, vehicular accidents. Under persistent stress an individual suffers from spiritual riots within himself. 
5.2 Spiritual paths such as yoga and holistic healing methods such as paranoiac healing and Reiki speak of a luminous energy body that encircles an individual's physical body. This is composed of subtle particles and intimately relates one's emotional conditions. Under chronic stress, this energy body and aura gets depleted due to inadequate absorption of life force into body and the energy pathways or chakras are blocked with stagnant and toxic prana leading to imbalance in body, mind and spirit. An individual tends to lose his all-round composure and fails to look for situation within. A depleted or weaken aura can incapacitate one to remain connected to himself and even to the outside world. This sense of disconnectedness can cause depression in individuals.

\section{Objectives of the study}

6.1. To evaluate the level of stress among Army personnel.

6.2. To suggest measures to improve the stress coping measures of army personnel.

6.3. To recommend special measures to combat stress in the army personnel serving in insurgent and difficult areas.

The hypothesis formed was that:

\section{Hypothesis:}

7.1. The army personnel especially in the insurgent areas are stressed.

7.2. There is a relation between working conditions and stress among individuals.

7.3 Meditation provides an effective solution against stress.

\section{Survey of Literature}

8.1. Psychological and Social Science :A large number of researches have studied and researched the subject of stress from various angles. Major studies remain on work stress. Since soldier's stress primarily emerges from his place of work, it should fall under the category of work stress.

8.2 Work stress is caused due to the conditions of work. A satisfied work force is the result of different attitudes he or she receives at work place. A satisfied and unstressed workforce is directly related to the quality of work life. As the awareness increases among the population, it is necessary to produce better services.

8.3 This emphasizes the need to address problem in the work place systematically rather than simply focusing on mere interventions through stress management programmes.

\section{Studies on Stress on Indian Soldiers:}

9.1 Defence Institute of Psychological Research (DIPR), a laboratory of Defence Research and Development Organization (DRDO), R\&D concluded two studies on the psychosocial aspect of optimizing the operational efficiency of security forces to combat insurgency in 2004 and 2005. Since a large number of soldiers resorted to suicides, running amok and killing their comrades and officers as a result of prolonged and severe stress they were undergoing. It was found that the major outcome of studies were that stress was because of fear of torture, uncertain environments and domestic stresses.

9.2 Army has complimented certain short term measures like employing increased number of psychological councilors and giving more number of facilities like liberal leave and constructing more number of houses closer to the place of posting.

\section{Stress Management}

10.1 Stress has been considered both a requirement and a harmful event. A certain amount of good stress as a catalyst for achieving optimum performance but too much or too little stress can damage your health. There are a large number of physical and psychological stressors which can cause physical or mental breakdown. The stress can be managed in two ways:

(i) Individual Approach

(ii) Organizational approach

10.2 In the individual approach it is the personal responsibility to reduce the stress level by following the following techniques.

(i) Time Management

(ii) Exercises

(iii) Relaxation Techniques and

(iv) Social support

10.3.1 For coping strategies specific to the defence forces, it must be noted that the goal of stress management is not to eliminate the stress. Life will certainly be dull without joyful stressors to which all have to adjust and without de-stressors needing a response. Further stress may motivate towards peak performance. So even if possible, stress should not be eliminated from our life while maintaining life's quality and vitality. The 
researchers found that there is an optimum amount of stress, not too much and not too little that is healthy and prophylactic. Some of the ground level strategies to maintain desirable stresss are:
a) Good leadership
b) Effective training
c) Proper accommodation for soldiers
d) Support to the family
e) Education to the children of defence personnel
f) Liberal grant of leave
g) Rest and recoup
h) Communication facilities

10.3.2 However these are not permanent measures. Permanent measure is to make the mind stress immune. The most important and permanent solution for stress management is to introduce relaxation technique in the form of meditation or yoga. The relaxation technique i.e. meditation should be adopted on a regular basis in the morning everyday coupled with the morning exercise. The meditation relaxation is most effective; cost effective and practical is defence forces.

\section{Meditation to Reduce Stress:}

11.1 Meditation is simply a mental exercise that affects body processes just as physical exercise has certain psychological benefits. The purpose of meditation is to gain control over your attention so that you can choose what to focus upon rather than being subjected to the unpredictable and following the flow of environmental circumstances.

11.2 Meditation has its tradition grounded in eastern culture (of India and Tibet) but has been popularized well in western culture. The major exporter of meditation to western world has been the Maharishi Mahesh yogi. He developed a large worldwide and highly effective organization to teach Transcendental Meditation (TM) to a population of people experiencing more and more stress and searching for an escape. The simplicity of this technique with its effectiveness of its marketing by TM organization quickly led to its popularity.

\section{Types of Meditation}

12.1 Transcendental meditation TM is one form of meditative practice; other forms are Chakra (Cyclic) yoga, Mudra yoga, Zen meditation e.g., Rinzai Zen and Soto Zen and Suffism, are examples of other meditation systems. In Soto Zen meditation, common external objects are focused upon. Tibetan Buddhists use mandala geometrical figure to meditate upon. Rinzai Zen meditation uses Koans. Hindu meditation employs pranayama meaning life force. Jewish meditation focuses on repetitive prayers receiving the light of divine with each breath. Regardless of the type of meditations, generally one or two approaches are used. Meditation is concentrating or focusing of attention. You focus your attention ignoring any other internal or external stimuli in any other manner; you may focus your attention on an object, a figure or maybe a repetitive prayer. When you focus attention on any particular thing; all other internal or external stimuli are excluded.

\section{Benefits of Meditation}

13.1. Physical Effects of Meditation: Meditation is the most researched relaxation technique because it can be learned quickly and easily. The research findings evidence the physiological and psychological effects of mediation.

13.2 Physiological Effects: The physiological effects of mediation were discovered by early research on Indian yogis. In 1946 TheriseBrosse found that Indian yogis could control their heart beat rates and they could slow respiration (four to six breath permeate) decrease by $70 \%$ their ability to conduct electrical current (galvanic skin response); emit predominantly alpha waves and slow their heart rate to twenty-four beats fewer than normal. Studies have also found that meditation decreases the muscle tension. The decrease in galvanic response in an individual is an indication of lower stress level. It also stabilises autonomic nervous system. The meditation has been demonstrated to have positive effects on blood pressure, lowering glucose line cortisol. Studies have found a decrease of expenses in the use of health services on meditators. This in turn saves company's money on the health insurance. It is found that meditation results in decreased consumption of oxygen, heart rate and alpha brain wave emissions; it increases skin resistance, decreases blood lactate and $\mathrm{CO} 2$ production.

13.3 Psychological Effects: Mind cannot be separated from the body. Physiological effects of meditation have psychological implications. It has been found by many studies that psychological health of meditators is better than the non-meditators. Meditators have been found to have less anxiety and have internal locus of control, 
greater self actualization, more positive feelings after encountering a stressor, improvement in the sleep behavior and general state of positive health. Meditation decreases drug abuse, reduces fears and phobia and showed potential for stress management. Keeping the importance of Yoga for getting a permanent solution for stress in the Army present study was taken up, using Yoga as the base for permanent solution.

\section{Methodology}

The mediation experts trained by Art of Living team were specially earmarked to guide the yoga meditation to selected samples at the institute level and in the army units to soldiers selected from amongst all ranks. A comparison of Blood Pressure, Cholesterol and Sugar was carried out before the start of meditation and after doing meditation and compared in all cases to measure the effect $t$ of meditation on parameters indicating stress. The progress of the meditation was regularly measured by various medical instruments and the progress regularly tabulated and graphed to evaluate the success rate. The health state at the start of the experiment was evaluated stage by stage till the completion.

\section{Area of Study:}

The all ranks of Indian Army i.e., Officers, Junior Commissioned Officers (JCO) and soldiers in insurgency prone and difficult areas specially Assam and Jammu Kashmir areas have been found stressed. The cases of soldiers running amok, of suicides and fratricides are reported maximum from these two areas. A study by the DIPR, a defence research organization also found that in these two areas the soldiers being stressed more, need of obviating stress or channelizing it for optimizing the efficiency of performance is a necessity. Keeping this in mind the North Eastern Sector of India was chosen for conducting the experiment. Due permission form higher Army authorities was obtained after presenting the project plan. Considering the motive of study useful for the Army, not only the permission was granted by the Army for conduct of experiment but also all possible administrative help was received from the units and medical organizations. Two units were selected in the North eastern Sector one deployed in relatively lesser insurgency area while the other deployed in deep insurgency area.

\section{Sample Selection}

16.1. Three groups of samples between the age group 30-50 with odd samples with differing age for checking purposes were selected(a) First group of 37 faculty members from BhaiMaha Singh College of Engineering (b) Second group of 51 soldiers living and working in relevantly less insurgent areas (c) Third group of 115 soldiers from deep insurgency areas. A group of 37 from a civil institution was chosen for presenting a comparison in civil conditions vis-à-vis Army environment. A meditation camp under the able guidance of a qualified teacher from Art of Living team was organsiedfor a period of two weeks.

16.2 Two samples of 51 (fifty one) and 115 (one hundred and fifteen) army personal were selected from 2 Army units in North Eastern sector, the first one deployed in less insurgency area while the second one employed in deep insurgency area. The troops included all ranks i.e. officers, junior commissioned officers, non-commissioned officers between the age 30 to 50. The meditation camp was organization for two weeks each in both these location under experts in meditation through Army Sources and locally trained instructors of Art of Living. The biological parameters were measured before and after the meditation to find out the effect on reduction in stress level.

\section{Data collection:}

17.1 The BP (Systolic and Diastolic), Cholesterol, Sugar fasting and PP of each individuals were measured before of the start of meditation and at the end of fifteen days campIt was conducted for a period of two weeks and the biological stress parameters were measured before and after the conduct of meditation camp. The assistance of Adesh Hospital, Muktsar was taken for taking the blood samples and testing in the laboratory of 37 samples at Muktsar. For the Samples from Army assistance from Army Medical units were obtained. The results of these parameters were recorded, tabulated and also represented graphically.

17.2 The meditation exercise was conducted under the expert teachers in 2011. The parameters selected were as under:

a) Measurement of blood pressure systolic and diastolic.

b) Measurement of Gulucolactate fasting.

c) Measurement of Gulucolactate normal PP

d) Measurement of Cholesterol 
18. Tools:

18.1 The variations in crucial measurable parameters were measured with the following test equipment:
a) Stethoscope
b) Blood pressure measuring instrument
c) Syringes for taking blood and small bottles for collecting the samples, cotton and spirit.
d) Desiccators
e) Elisa-Auto analyzer(Semi-auto)
f) Cell counter
g) Autoclave
h) Glucometer

\section{Result andAnalysis}

19.1 A Wilcoxon Signed Rank test was carried out to test the hypothesis 1 i.e., The Army personnel especially in insurgent areas are stressed. The Wilcoxon signed-rank test is a non-parametric statistical hypothesis test used when comparing two related samples, matched samples, or repeated measurements on a single sample to assess whether their population mean ranks differ (i.e. it is a paired difference test). It can be used as an alternative to the paired Student's t-test, $t$-test for matched pairs, or the $t$-test for dependent samples when the population cannot be assumed to be normally distributed. (1)

\subsection{Assumptions}

1. Data are paired and come from the same population.

2. Each pair is chosen randomly and independent.

3. The data are measured on an interval scale (ordinal is not sufficient because we take differences), but need not be normal.

19.3Here the population taken was army and civil personnel between the age groups of 30-50 in three groups with an odd variation for internal check and test purposes. The test was carried using SPSS statistical programme.

19.4The stress level among Army Personnel and civilians was compared by forming three teams between age group of 27-50 i.e., one of 37 civilians from BhaiMaha Singh College in Muktsar in a profession of teaching; 51 members of Army Personnel in relevantly less insurgent areas and 115 Army personnel in intense insurgent areas. Their Systolic Blood Pressure and Diastolic Blood pressures; Cholesterol and Sugar levels in fast conditions were measured before the start of meditation practice and also after the meditation. The results of various comparisons and their analysis with the help of SPSS are given out in the following tables:

Table 1: Wilcoxon Signed Ranks Test statistics of BP, Cholesterol and Sugar before meditation of 51 Army personnel in Lesser insurgency areas and 37 Civilians before meditation

\begin{tabular}{|l|r|r|r|r|}
\hline & $\begin{array}{l}\text { Systolicbefore51 } \\
\text {-Systolicbefore37 }\end{array}$ & $\begin{array}{c}\text { Diastolicbefore51 } \\
\text { Diastolicbefore37 }\end{array}$ & $\begin{array}{c}\text { Cholesterolbefore51 } \\
\text { - cholesterolbefore37 }\end{array}$ & $\begin{array}{c}\text { Sugarfast51 - } \\
\text { Sugarfastbefore37 }\end{array}$ \\
\hline Z & $-5.105^{\mathrm{a}}$ & $-3.794^{\mathrm{a}}$ & $-3.832^{\mathrm{a}}$ & $-4.899^{\mathrm{a}}$ \\
$\begin{array}{l}\text { Asymp. Sig. (2- } \\
\text { tailed) }\end{array}$ & .000 & .000 & .000 & .000 \\
\hline
\end{tabular}

a. Based on negative ranks.

b. Wilcoxon Signed Ranks Test

Analysis 1: From table 1 Systolic, Diastolic, Cholesterol and Sugar in Fast condition before meditation of 51 samples from Army personnel in relatively lesser insurgency area and of 37 civilians faculty of BMS College of Engineering were compared through Wilcoxon Signed Ranks Test. The test showed a significant difference between Army and Civilian Systolic, Diastolic, Cholesterol and Sugar in Fast condition where Civilians are in a significantly better condition because of $z$ value of $5.105,3.794,3.832$ and 4.899 which are well above 1.96, 2.58 and even 3 .

Table 2: Wilcoxon Signed Ranks Test stat0istics of BP, Cholesterol and Sugar before meditation of 115 Army personnel in Lesser insurgency areas and 37 Civilians before meditation 
Meditation for stress reduction in Indian Army- An Experimental Study

\begin{tabular}{|l|r|r|r|r|}
\hline & $\begin{array}{r}\text { Systoicbefore115 } \\
\text { Systolicbefore37 }\end{array}$ & $\begin{array}{c}\text { Diastolicbefore115 } \\
\text { Diastolicbefore37 }\end{array}$ & $\begin{array}{c}\text { Cholestrolbefore115 } \\
\text { cholesterolbefore37 }\end{array}$ & $\begin{array}{c}\text { Sugarbefore115- } \\
\text { Sugarfastbefore37 }\end{array}$ \\
\hline Z & $-5.013^{\mathrm{a}}$ & $-5.162^{\mathrm{a}}$ & $-5.164^{\mathrm{b}}$ & $-2.148^{\mathrm{a}}$ \\
$\begin{array}{l}\text { Asymp. Sig. (2- } \\
\text { tailed) }\end{array}$ & .000 & .000 & .000 & .032 \\
\hline
\end{tabular}

a. Based on negative ranks.

b. Based on positive ranks.

c. Wilcoxon Signed Ranks Test

Analysis 2: From table 2 Systolic, Diastolic, Cholesterol and Sugar in Fast condition before meditation of 115 samples from Army personnel in relatively lesser insurgency area and of 37 civilians faculty of BMS College of Engineering were compared through Wilcoxon Signed Ranks Test. The test showed a significant difference between Army and Civilian Systolic, Diastolic, Cholesterol and Sugar in Fast condition where Civilians are in a significantly better condition because of $z$ value of 5.013, 5.162, 5.164 and 2.148 which are well above 1.96 and 2.58 and the first three results of $z$ being even meore 3 .

Table 3: Wilcoxon Signed Ranks Test Comparison of BP, Cholesterol and Sugar before meditation of 51 Army personnel in Lesser insurgency areas and 115 Army persons in deeper insurgency areas before meditation

\begin{tabular}{|l|r|r|r|r|}
\hline & $\begin{array}{c}\text { Systoicbefore151 - } \\
\text { Systolicbefore51 }\end{array}$ & $\begin{array}{c}\text { Diastolicbefore151 - } \\
\text { Diastolicbefore51 }\end{array}$ & $\begin{array}{c}\text { cholestrolbefore151 - } \\
\text { Cholesterolbefore51 }\end{array}$ & $\begin{array}{c}\text { Sugarbefore151 - } \\
\text { Sugarfast51 }\end{array}$ \\
\hline Z & $-2.436^{\mathrm{a}}$ & $-6.224^{\mathrm{a}}$ & $-6.222^{\mathrm{b}}$ & $-6.024^{\mathrm{b}}$ \\
$\begin{array}{l}\text { Asymp. Sig. (2- } \\
\text { tailed) }\end{array}$ & .015 & .000 & .000 & .000 \\
\hline
\end{tabular}

a. Based on negative ranks.

b. Based on positive ranks.

c. Wilcoxon Signed Ranks Test

Analysis 3: From Table 3 Systolic, Diastolic, Cholesterol and Sugar in Fast condition before meditation of 115 samples from Army personnel in relatively lesser insurgency area and 115 Army persons in deeper insurgency areas before meditation were compared through Wilcoxon Signed Ranks Test. The test showed a significant difference between Army Personnel in lesser insurgency areas to deep insurgency areas in Systolic, Diastolic, Cholesterol and Sugar in Fast condition where Army Personnel in lesser insurgency areas are in a significantly better condition to Army personnel in deep insurgency areas because of $z$ value of $2.436,6.224,6.222$ and 6.024 which are well above 1.96 and the last three results of $z$ being even more 2.58 and 3 .

Second hypothesis

With the above results the second hypothesis that there is a relation between working conditions and stress among individuals is also proved.

Third Hypothesis

To prove the third hypothesis that "Meditation provides an effective solution against stress"; a comparative of BP, Cholesterol and Sugar is carried out between all the samples in different groups before meditation and after meditation and also between the groups with the help of Wilcoxon Signed Ranks Test.

Table 4: Wilcoxon Signed Ranks Test Statistics of BP, Cholesterol and Sugar before and after meditation of 37 Civilians before meditation

\begin{tabular}{|l|r|r|r|r|}
\hline & $\begin{array}{r}\text { Systolicafter37 - } \\
\text { Systolicbefore37 }\end{array}$ & $\begin{array}{c}\text { Distolicafter37 - } \\
\text { Diastolicbefore37 }\end{array}$ & $\begin{array}{c}\text { Cholestrolafter37 - } \\
\text { cholesterolbefore37 }\end{array}$ & $\begin{array}{c}\text { Sugarfast37 - } \\
\text { Sugarfastbefore37 }\end{array}$ \\
\hline Z & $-2.822^{\mathrm{a}}$ & $-3.928^{\mathrm{a}}$ & $-3.726^{\mathrm{a}}$ & $-2.412^{\mathrm{a}}$ \\
Asymp. Sig. (2-tailed) & .005 & .000 & .000 & .016 \\
\hline
\end{tabular}

a. Based on positive ranks.

b. Wilcoxon Signed Ranks Test 
Analysis 4: From table 4 Systolic, Diastolic, Cholesterol and Sugar in Fast condition before and after meditation of 37 civilians, the faculty of BMS College of Engineering were compared through Wilcoxon Signed Ranks Test. The test showed a significant difference between before and after Systolic, Diastolic, Cholesterol and Sugar in Fast condition where after meditation there was a significant because of $z$ value of 3.928 and 3.726 were are well above 1.96, 2.58 and even $3 \mathrm{z}$ value 2.412 was well above 1.96 and 2.822 was well above 1.96 and 2.58. It showed that improved in Diastolic and Cholesterol is much more significant.

Table 5: Wilcoxon Signed Ranks Test Statistics of BP, Cholesterol and Sugar before and after meditation of 51 Army Personnel

\begin{tabular}{|l|r|r|r|r|}
\hline & $\begin{array}{r}\text { systolicafter51 - } \\
\text { Systolicbefore51 }\end{array}$ & $\begin{array}{c}\text { Distolicafter51 - } \\
\text { Diastolicbefore51 }\end{array}$ & $\begin{array}{c}\text { Cholestrolafter51 - } \\
\text { Cholesterolbefore51 }\end{array}$ & $\begin{array}{c}\text { Sugarfaster51 - } \\
\text { Sugarfast51 }\end{array}$ \\
\hline Z & $-6.289^{\mathrm{a}}$ & $-6.250^{\mathrm{a}}$ & $-6.268^{\mathrm{a}}$ & $-6.243^{\mathrm{a}}$ \\
Asymp. Sig. (2-tailed) & .000 & .000 & .000 & .000 \\
\hline
\end{tabular}

a. Based on positive ranks.

b. Wilcoxon Signed Ranks Test

Analysis 5: From table 5 Systolic, Diastolic, Cholesterol and Sugar in Fast condition before and after meditation of 51 Army Personnel, were compared through Wilcoxon Signed Ranks Test. The test showed a significant difference between before and after Systolic, Diastolic, Cholesterol and Sugar in Fast condition where after meditation there was a significant because of all the $z$ value i.e., 6.289, 6.250, 6.268 and 6.243 are well above $1.96,2.58$ and even 3 .

Table 6: Wilcoxon Signed Ranks Test Statistics of BP, Cholesterol and Sugar before and after meditation of 115 Army Personnel

\begin{tabular}{|l|r|r|r|r|}
\hline & $\begin{array}{l}\text { Systolicafter115 - } \\
\text { Systolicbefore115 }\end{array}$ & $\begin{array}{l}\text { Disatolicafter115 - } \\
\text { Distolicbefore115 }\end{array}$ & $\begin{array}{c}\text { Cholestrolafter115 - } \\
\text { Cholestrolbefereo115 }\end{array}$ & $\begin{array}{l}\text { Sugarfastafter115 - } \\
\text { Sugarfastbefore115 }\end{array}$ \\
\hline Z & $-9.210^{\mathrm{a}}$ & $-9.334^{\mathrm{a}}$ & $-9.180^{\mathrm{a}}$ & $-8.928^{\mathrm{a}}$ \\
Asymp. Sig. (2- & .000 & .000 & .000 & .000 \\
tailed) & & & & \\
\hline
\end{tabular}

a. Based on positive ranks.

b. Wilcoxon Signed Ranks Test

Analysis 6: From table 6 Systolic, Diastolic, Cholesterol and Sugar in Fast condition before and after meditation of 115 Army Personnel, were compared through Wilcoxon Signed Ranks Test. The test showed a significant difference between before and after Systolic, Diastolic, Cholesterol and Sugar in Fast condition where after meditation there was a significant because of all the $z$ value i.e., 9.210, 9.334, 9.180 and 8.928 are well above 1.96, 2.58 and even 3 .

Table 14. Wilcoxon Signed Ranks Test Statistics of Sugar PP before and after meditation of 51 and 115 Army Personnel respectively

\begin{tabular}{|l|r|r|}
\hline & $\begin{array}{l}\text { SugarPPafter51 - } \\
\text { SugarPPbefore51 }\end{array}$ & $\begin{array}{l}\text { SugarPPafter115 - } \\
\text { SugarPPbefore115 }\end{array}$ \\
\hline Z & $-5.316^{\mathrm{a}}$ & $-9.300^{\mathrm{a}}$ \\
Asymp. Sig. (2-tailed) & .000 & .000 \\
\hline
\end{tabular}

a. Based on positive ranks.

b. Wilcoxon Signed Ranks Test

Analysis 7: From table 7 Sugar in PP condition before and after meditation of 51 and 115 Army Personnel Groups were compared through Wilcoxon Signed Ranks Test. The test showed a significant difference between Sugar in PP condition before and after meditation there was a significant because of all the $z$ value i.e., 5.316 in Sugar PP before and after of 51 samples group and 9.300 of 115 samples group are much above 1.96, 2.58 and even 3 . 
Table 8. Wilcoxon Signed Ranks Test Statistics of Sugar PP before and after meditation of 51 compared with 115 Army Personnel

\begin{tabular}{|l|r|r|}
\hline & \multicolumn{1}{|c|}{ SugarPPbefore115- } & \multicolumn{2}{|c|}{$\begin{array}{c}\text { SugarPPafter115 - } \\
\text { SugarPPafter51 }\end{array}$} \\
\hline$Z$ & $-2.699^{\mathrm{a}}$ & $-2.298^{\mathrm{a}}$ \\
SugarPPbefore51 & .007 & .022 \\
\hline
\end{tabular}

a. Based on negative ranks.

b. Wilcoxon Signed Ranks Test

Analysis 8: From table 8 Sugar in PP condition before and after meditation of 51 was compared with Sugar in PP condition before and after 115 Army Personnel Groups through Wilcoxon Signed Ranks Test. The test showed a significant difference between Sugar in PP condition in both the cases i.e., sugar PP before meditation of 51 samples when compared with sugar PP before meditation was 2.699 i.e., much above 1.96 and $2.58 \mathrm{Z}$ values. Similarly sugar PP after meditation of 51 samples when compared with 115 samples of sugar PP after meditation, there was a significant difference in $\mathrm{z}$ value i.e., 2.298 which is much above 1.96 and 2.58.

The results in Analysis 1-8 go to prove that the third Hypothesis is proved.

\section{Systolic Blood Pressure}

The blood pressure (systolic) was measured for all the individuals before and after the meditation. The group one consisting of 51 all ranks was in the range of 27 years to 51 years. The range of age group consisting of 115 soldiers also about the same. In the normal course the young people should have the systolic blood pressure in the range of 120 to 135 but it was found from the data that before the meditation the average $\mathrm{BP}$ of younger group was in the range of 130 to 150 . This indicated that the group of 50 individuals was having higher blood pressure which showed that the soldiers in younger group were found to be more stressed. From the data it was found that the maximum numbers of soldiers were married; only nine individuals were single. One of the reasons of stress was that the soldiers were staying single after marriage under compulsion of service conditions. Similarly from the data of vegetarian and non-vegetarian, it was observed that the Blood Pressure of nonvegetarian and those drinking alcohol was higher. The average systolic blood pressure of non-vegetarians and drinking soldiers was 135. Similarly the diastolic blood pressure of all individual ranged from 80 to 100 . The maximum number lies in the range 90 to 100 . Young healthy person are expected to have diastolic BP in the range 80-85. The lower blood pressure is also found to be following the same pattern as the systolic blood pressure. This again gives an indication of stressed individuals.

\section{Effect of meditation on blood pressure:}

After doing meditation for seven days the systolic and diastolic pressure was again measured and recorded. It can be found from the table that each individual, exception being Sr. No. 2 and 17, showed a decrease in BP to the range of 4 to 6 points indicating the reduction of both systolic and diastolic B.P. by doing seven days meditation. This showed the decrease in the stress level. It showed that that the exercise (Meditation) done regularly every day could reduce the B.P. and in turn reduce the stress level.

\section{Effect of Meditation on Cholesterol Level:}

The cholesterol level was measured before the meditation and after doing it on the similar lines as for the blood pressure level. Prior to start of the meditation the cholesterol level of the group ranged from 180 to 230 points which is slightly higher than the normal level. This too indicated the effect of stress. After doing meditation for fifteen days, the level of cholesterol level measured. The reduction of cholesterol level after doing meditation was remarkable; this reduction ranged between 5 to 15 points giving an indication of reduction of stress level. The exception were however Sr. Nos. 9, 15, 19 and 26 where no reduction of cholesterol level was observed. This can be considered as exceptions. The effect of reduction of cholesterol leading to reduction of stress level was similar to reduction of blood pressure.

\section{Effect of Meditation on Sugar (Glucolactate):}

The blood samples from all the soldiers were obtained empty stomach before the start of the meditation. After a period of two hours the blood sample was again taken. The soldiers were made to eat their breakfast immediately after taking the first blood sample. The readings for sugar level empty stomach and after eating breakfast and doing meditation were recorded as shown in the table. 
The reduction of fasting sugar level was noted and it was found that the reduction was on the average $5-10$ points. In one case i.e. Sr. No. 4 , the reduction was 14 points. It was also seen that in a few cases like S.Nos. 5, 6 and 12 the sugar level went up rather than coming down. This was regarded to be exceptional cases or may be due to some error in recording.

Similarly it is seen from the data of PP level sugar; on the average the reduction was noted 5 to 10 points. The results of both fasting and PP level show that the sugar level reduces by doing meditation. This was the result of doing meditation for a period of seven days. It is expected that if the meditation is done daily there would be further reduction of sugar level and would stabilize at the normal of glucolactate and hence stress level will be reduced.

\section{Validation of the Effect of Meditation on Blood Pressure, Sugar and Cholesterol}

To confirm and validate the results obtained from the first group the meditation exercise was again done on a second group of 51 people under similar conditions and under the same expert with different individuals.

The record for blood pressure, systolic and diastolic was obtained. Cholesterol level and sugar level; both for normal and fasting was done by the same person and with the same equipment under similar conditions. The results of all parameters were tabulated and graphs drawn.

The results so obtained were very much akin to the results of the first group. The reductions in blood pressure level were again in the range of $4-6$ points; sugar level was in the range of $4-6$ points; the cholesterol level reduction was 10 to 15 points.

The results of the second group confirmed/validated the results obtained from first group. This proved that if the Army personnel do meditation daily for half an hour, coupled with morning exercise the stress level among the Army will be greatly reduced.

It can be seen from the tables that there is a decrease in blood pressure, sugar level and cholesterol level as compared to the start level i.e., before the beginning of the exercise. On the average there is a decrease of the level of these biological parameters from $8-10 \%$ exception being only two to three cases where the expected results were not on expected lines. These are taken as exceptions. A Questionnaire was also administered to all the meditators to further validate the study findings.

\section{Conclusion:}

The stress has affected armed forces in a major way. The peculiar environment and operating conditions provide a breeding ground for stress. In order to reduce stress level there is a need to manage physiological and psychological effects of the stress. There is no single particular method to eliminate all the stress levels. Apart from the physical incentives/concessions being now given to Armed Forces in term of leave, accommodation, ration and free education for children requirement exists for reduction of stress level or convert the existing stress into a productive use. No other method than meditation has yet proved to be effective in permanent reduction of stress. By incorporating the relaxation technique through meditation in a regular system suitably in the morning coupled with morning exercise which army personnel routinely perform. Meditation for half an hour daily will certainly reduce the stress level and armed personnel will be in a state give their optimal performance. This reduction of stress level will reduce the fratricide and suicide cases to a great extent.

\section{Scope for future research}

The 'quality of work life' varies from work place to workplace and with the type of work and the stress on a worker varies accordingly. The soldiers work under the most difficult conditions and do not have the quality of work life as does a teacher or a professor. The harsh conditions cause heavy stress on the soldiers taking life in number of cases. This is why there are much more suicide cases in Army than in civil. Nothing much has been done to improve the quality of work life of these soldiers; their remuneration too does not match the quality of work life. It is very important that a detailed study of various parameters of quality of work life and the remuneration paid to the soldier in relation to a civilian be compared and alternatives suggested. Also recommended is the study of stressed conditions in peace and field conditions of a soldier. Similarly the study can also be carried out through a comparison of quality of work life of a soldier with that of an officer in Army.

\section{Bibliography}

[1]. Allison J (1970). Respiratory changes during Transcendental Meditation. Lancet No. 7651 833-34

[2]. Bhargava SC, Sharma S and Aggarwal BV (1980). Neuroticism profile in coronary heart diseases - Indian Journal of Psychiatry, 22, D-62

[3]. Beer TA and Bhagat RS (1985). Human stress and cognition in organization. An integrated perspective. New York, John Willey and Sons.

[4]. Carrington J. (1998). The elementary book of meditation. Boston

[5]. Fink N (1998). An emerging spiritual practice. Jewish Meditation Tikkun 13 60-61 
[6]. Gauthen NR and CA Prymak. (1977). Meditation versus relaxation experience with Transcendental Meditation. Journal of Consulting and Clinical Psychology 45 496-97

[7]. Gupta PK (1981). Factor analytic study of coronary prone personality behavior presented in the Indian Science Congress association. IIT Varanasi.

[8]. Hans Selye, (1956). The Stress of Life, New York. McGraw Hill Book Co.

[9]. McGujion J (1994). Stress management through progressive relaxation. International Journal of Stress Management-205-14

[10]. Matsumoto M and JC Smith. (2001). Progressive muscle relaxation, breathing exercises and ABC Relaxation Theory. The Journal of Clinical Psychology 1551-57-

[11]. Pestonjee D M \&Bagchi R (1978): Need pattern among coronary patients. Indian Journal of Psychiatry 20, 193-195

[12]. Pestonjee (1991). DIH. Stress and coping: The Indian Experience. New Delhi: Sage.

[13]. Pestonjee D M \&Muncherji (1991). Executive Health: A neglected aspect of HRD, Vikalpa 16(3), July-Sept, 21, 34

[14]. Pareek (1993). Making organizational roles effective. New Delhi. Tata McGraw Hill.

[15]. Robertkeith (1970). Psychological effects of transcendental meditation Science. 167 1751-54]

[16]. Wolf S. and Goodell H (1968), Stress and disease. Springfield II, Thomas

[17]. Brown R.P. and Gerbarg PL. (April 2009). Sudarshankriya. "Yogic Breathing in the treatment of stress, Anxiety smoking, headache relief and general state of positive mental health."

[18]. Cotman CW and Engesser C. (April 2002)."Exercise Enhances and protects Brain Function"

[19]. Davis, McKay and E Shidman (May,2008). "Relaxation and stress reduction workbook"

[20]. Jon Kabat-Zinnetal. (July 2012). Effectiveness of meditation - based reduction programme in the treatment of Anxiety Disorder"

[21]. Lehrer. (Jan 1996) Variety of Relaxation methods and their Unique Effects

[22]. McGuigan EJ. (April 1994). Stress Management through Progressive Relaxation”, International Journal of Stress Management

[23]. Thomas H. Budzynski, Johann Stoyna and C Adler. "Feedback Induced Muscle Relaxation" (Sept - 1970)

[24]. Vyas R and Dixit N, (Oct-2002). "Effect of meditation on respiratory system, and lipid profile", Indian Journal of Physiological Pharmacology.

[25]. Johnson, PR and Indvikj (1997) Stressful Work, Citizenship Behaviour and Intention to Leave the Organization in a High Turnover Environment.

[26]. Lazarous R.S (1966). Psychological stress and the coping process.

[27]. Lowry, Richard. "Concepts \& Applications of Inferential Statistic". Retrieved 24 March 2011.

[28]. McGrath, J. E.; Beehr, T. A. (1990). "Time and the Stress Process: Some Temporal Issues in the Conceptualization and Measurement of Stress".

[29]. Siegel, Sidney (1956). Non-parametric statistics for the behavioral sciences. New York: McGraw-Hill. pp. $75-83$.

[30]. Wilcoxon, Frank (Dec 1945). "Individual comparisons by ranking methods". Biometrics Bulletin1 (6): 80-83. 